\title{
The dominant role of impurities in the composition of high pressure noble gas plasmas
}

\section{Citation for published version (APA):}

Martens, T., Bogaerts, A., Brok, W. J. M., \& Dijk, van, J. (2008). The dominant role of impurities in the composition of high pressure noble gas plasmas. Applied Physics Letters, 92(4), 041504-1/3. [041504]. https://doi.org/10.1063/1.2839613

DOI:

$10.1063 / 1.2839613$

Document status and date:

Published: 01/01/2008

\section{Document Version:}

Publisher's PDF, also known as Version of Record (includes final page, issue and volume numbers)

\section{Please check the document version of this publication:}

- A submitted manuscript is the version of the article upon submission and before peer-review. There can be important differences between the submitted version and the official published version of record. People interested in the research are advised to contact the author for the final version of the publication, or visit the $\mathrm{DOI}$ to the publisher's website.

- The final author version and the galley proof are versions of the publication after peer review.

- The final published version features the final layout of the paper including the volume, issue and page numbers.

Link to publication

\section{General rights}

Copyright and moral rights for the publications made accessible in the public portal are retained by the authors and/or other copyright owners and it is a condition of accessing publications that users recognise and abide by the legal requirements associated with these rights.

- Users may download and print one copy of any publication from the public portal for the purpose of private study or research.

- You may not further distribute the material or use it for any profit-making activity or commercial gain

- You may freely distribute the URL identifying the publication in the public portal.

If the publication is distributed under the terms of Article 25fa of the Dutch Copyright Act, indicated by the "Taverne" license above, please follow below link for the End User Agreement:

www.tue.nl/taverne

Take down policy

If you believe that this document breaches copyright please contact us at:

openaccess@tue.nl

providing details and we will investigate your claim. 


\title{
The dominant role of impurities in the composition of high pressure noble gas plasmas
}

\author{
T. Martens ${ }^{\mathrm{a})}$ and A. Bogaerts \\ Department of Chemistry, University of Antwerp, Universiteitsplein 1 B-2610 Antwerp, Belgium \\ W. J. M. Brok and J. V. Dijk \\ Department of Applied Physics, Eindhoven University of Technology, 5600 MB Eindhoven, The Netherlands
}

(Received 5 November 2007; accepted 14 January 2008; published online 1 February 2008)

\begin{abstract}
We present in this letter how a molecular gas such as nitrogen at different levels of impurity dominates the ionic composition of an atmospheric pressure noble gas plasma such as in helium. The positive charge in the discharge is only determined by helium ions if the discharge gas contains less than 1 ppm of impurity. Above this impurity level, the positive charge is completely determined by the impurity nitrogen. The higher the relative nitrogen concentration, the more $\mathrm{N}_{4}^{+}$dominates over $\mathrm{N}_{2}^{+}$. If the impurity level is between 1 and about $20 \mathrm{ppm}, \mathrm{N}_{2}^{+}$is clearly the most abundant positive ion but for higher levels of impurity, $\mathrm{N}_{4}^{+}$almost completely determines the positive charge. (C) 2008 American Institute of Physics. [DOI: 10.1063/1.2839613]
\end{abstract}

The influence of different levels of impurity in gas discharges is important in both experimental and simulation research efforts. In experimental research, one automatically encounters different levels of gas (im)purity since two experimental setups are seldom completely the same because of the different reactor designs and because not always the same quality grade gas is being used. ${ }^{1,2}$ In simulations, this purity level is sometimes derived from estimations ${ }^{1}$ or sometimes used as a fitting parameter to match a fundamental parameter such as gas voltage to the experimental value. ${ }^{3}$ Therefore, it is important to investigate the influence of different levels of impurity in order to obtain a more general insight on this matter.

The investigation is carried out using a 2D fluid model, included in the Plasimo modeling framework ${ }^{4}$ for an atmospheric pressure glow (APG) discharge in a dielectric barrier discharge (DBD) setup.

In this study, we considered either pure helium or helium gas with a certain amount of nitrogen present. The modeled species are the background gases $\mathrm{He}$ and $\mathrm{N}_{2}$, the electrons, the ions $\mathrm{He}^{+}, \mathrm{He}_{2}^{+}, \mathrm{N}_{2}^{+}$, and $\mathrm{N}_{4}^{+}$, the metastable helium atoms $\mathrm{He}_{m}^{*}$, and the helium excimers $\mathrm{He}_{2}^{*}$. The ions $\mathrm{N}^{+}$and $\mathrm{N}_{3}^{+}$and the chemically related atomic $\mathrm{N}$ were not taken into account for matters of simplicity. These particles are of minor importance in the ionic composition of the atmospheric plasma because $\mathrm{N}^{+}$is very quickly converted into $\mathrm{N}_{2}^{+}$through $\mathrm{N}^{+}$ $+\mathrm{N}+\mathrm{He} \rightarrow \mathrm{N}_{2}^{+}+\mathrm{He}$ and the degradation of $\mathrm{N}_{3}^{+}$by $\mathrm{N}_{3}^{+}+\mathrm{N}$ $\rightarrow \mathrm{N}_{2}^{+}+\mathrm{N}_{2}$ is about 6.5 times faster ${ }^{5}$ than the equivalent degradation reaction of $\mathrm{N}_{4}^{+}$, i.e., $\mathrm{N}_{4}^{+}+\mathrm{N} \rightarrow \mathrm{N}^{+}+2 \mathrm{~N}_{2}$. Inclusion of these particles would only lead to a possible amplification of the impurity effects. The energy dependent transport data and reaction coefficients of the electrons were calculated using BOLSIG (Ref. 6) and the transport data for the other species were obtained from literature. ${ }^{7,8}$ The chemical reaction set used in the model is composed from publications on discharge modeling found in literature , $^{1,9-11}$ and consists of 18 chemical reactions which are shown in Table I and an extra electron energy loss term for the production of radiative species. $^{12}$

\footnotetext{
a) Author to whom correspondence should be addressed. Electronic mail: tom.martens@ua.ac.be.
}

The experimental setup under consideration is very similar to the setup used by Massines et al. ${ }^{13}$ and Mangolini et $a l .{ }^{1}$ for the sake of comparison with experiment. The configuration consists of two parallel electrodes both covered with alumina dielectrics $\left(\epsilon_{r}=9\right)$ of $1 \mathrm{~mm}$ thickness. The distance between the dielectric surfaces is $5 \mathrm{~mm}$. One electrode is kept at ground potential and at the other a sinusoidal voltage is applied with a frequency of $10 \mathrm{kHz}$ and an amplitude of $2.6 \mathrm{kV}$. These conditions have been chosen as such because they allow us to obtain discharge breakdown for every purity level under study. It is worth to mention that a discharge configuration with the above-mentioned electrode

TABLE I. Reactions included in the model with their reaction coefficients. The first three reaction coefficients are calculated using BOLSIG. In reaction 16, $M$ denotes a heavy collision partner and the destruction frequency is taken from Golubovskii et al. ${ }^{11}$

\begin{tabular}{|c|c|c|}
\hline \multicolumn{2}{|c|}{ Number of reaction } & \multirow[t]{2}{*}{ Rate coeff } \\
\hline 1 & $e^{-}+\mathrm{He} \rightarrow e^{-}+\mathrm{He}_{m}^{*}$ & \\
\hline 2 & $e^{-}+\mathrm{He} \rightarrow 2 e^{-}+\mathrm{He}^{+}$ & $f(\sigma)$ \\
\hline 3 & $e^{-}+\mathrm{He}_{m}^{*} \rightarrow 2 e^{-}+\mathrm{He}^{+}$ & $f(\sigma)$ \\
\hline 4 & $e^{-}+\mathrm{He}_{2}^{+} \rightarrow \mathrm{He}_{m}^{*}+\mathrm{He}$ & $8.9 \times 10^{-9}\left(\frac{T_{g}}{T_{e}}\right)^{1.5} \mathrm{~cm}^{3} \mathrm{~s}^{-1}$ \\
\hline 5 & $e^{-}+\mathrm{N}_{2}^{+} \rightarrow \mathrm{N}+\mathrm{N} \rightarrow \mathrm{N}_{2}$ & $4.8 \times 10^{-7}\left(\frac{T_{g}}{T_{e}}\right)^{0.5} \mathrm{~cm}^{3} \mathrm{~s}^{-1}$ \\
\hline 6 & $e^{-}+\mathrm{N}_{4}^{+} \rightarrow \mathrm{N}_{2}+\mathrm{N}_{2}$ & $2 \times 10^{-6}\left(\frac{T_{g}}{T_{e}}\right)^{0.5} \mathrm{~cm}^{3} \mathrm{~s}^{-1}$ \\
\hline 7 & $\mathrm{He}^{+}+2 \mathrm{He} \rightarrow \mathrm{He}_{2}^{+}+\mathrm{He}$ & $1.1 \times 10^{-31} \mathrm{~cm}^{6} \mathrm{~s}^{-1}$ \\
\hline 8 & $\mathrm{He}_{2}^{+}+\mathrm{N}_{2} \rightarrow \mathrm{He}_{2}^{*}+\mathrm{N}_{2}^{+}$ & $1.4 \times 10^{-9} \mathrm{~cm}^{3} \mathrm{~s}^{-1}$ \\
\hline 9 & $\mathrm{~N}_{2}^{+}+2 \mathrm{~N}_{2} \rightarrow \mathrm{N}_{4}^{+}+\mathrm{N}_{2}$ & $1.9 \times 10^{-29} \mathrm{~cm}^{6} \mathrm{~s}^{-1}$ \\
\hline 10 & $\mathrm{~N}_{2}^{+}+\mathrm{N}_{2}+\mathrm{He} \rightarrow \mathrm{N}_{4}^{+}+\mathrm{He}$ & $1.9 \times 10^{-29} \mathrm{~cm}^{6} \mathrm{~s}^{-1}$ \\
\hline 11 & $\mathrm{~N}_{4}^{+}+\mathrm{N}_{2} \rightarrow \mathrm{N}_{2}^{+}+2 \mathrm{~N}_{2}$ & $2.5 \times 10^{-15} \mathrm{~cm}^{3} \mathrm{~s}^{-1}$ \\
\hline 12 & $\mathrm{~N}_{4}^{+}+\mathrm{He} \rightarrow \mathrm{N}_{2}^{+}+\mathrm{N}_{2}+\mathrm{He}$ & $2.5 \times 10^{-15} \mathrm{~cm}^{3} \mathrm{~s}^{-1}$ \\
\hline 13 & $\mathrm{He}_{m}^{*}+2 \mathrm{He} \rightarrow \mathrm{He}_{2}^{*}+\mathrm{He}$ & $2 \times 10^{-34} \mathrm{~cm}^{6} \mathrm{~s}^{-1}$ \\
\hline 14 & $\mathrm{He}_{m}^{*}+\mathrm{He}_{m}^{*} \rightarrow \mathrm{He}_{2}^{+}+e^{-}$ & $1.5 \times 10^{-9} \mathrm{~cm}^{3} \mathrm{~s}^{-1}$ \\
\hline 15 & $\mathrm{He}_{m}^{*}+\mathrm{N}_{2} \rightarrow \mathrm{He}+\mathrm{N}_{2}^{+}+e^{-}$ & $5 \times 10^{-11} \mathrm{~cm}^{3} \mathrm{~s}^{-1}$ \\
\hline 16 & $\mathrm{He}_{2}^{*}+M \rightarrow 2 \mathrm{He}+M$ & $10^{-4} \mathrm{~s}^{-1}$ \\
\hline 17 & $\mathrm{He}_{2}^{*}+\mathrm{He}_{2}^{*} \rightarrow \mathrm{He}_{2}^{+}+2 \mathrm{He}+e^{-}$ & $1.5 \times 10^{-9} \mathrm{~cm}^{3} \mathrm{~s}^{-1}$ \\
\hline 18 & $\mathrm{He}_{2}^{*}+\mathrm{N}_{2} \rightarrow 2 \mathrm{He}+\mathrm{N}_{2}^{+}+e^{-}$ & $3 \times 10^{-11} \mathrm{~cm}^{3} \mathrm{~s}^{-1}$ \\
\hline
\end{tabular}




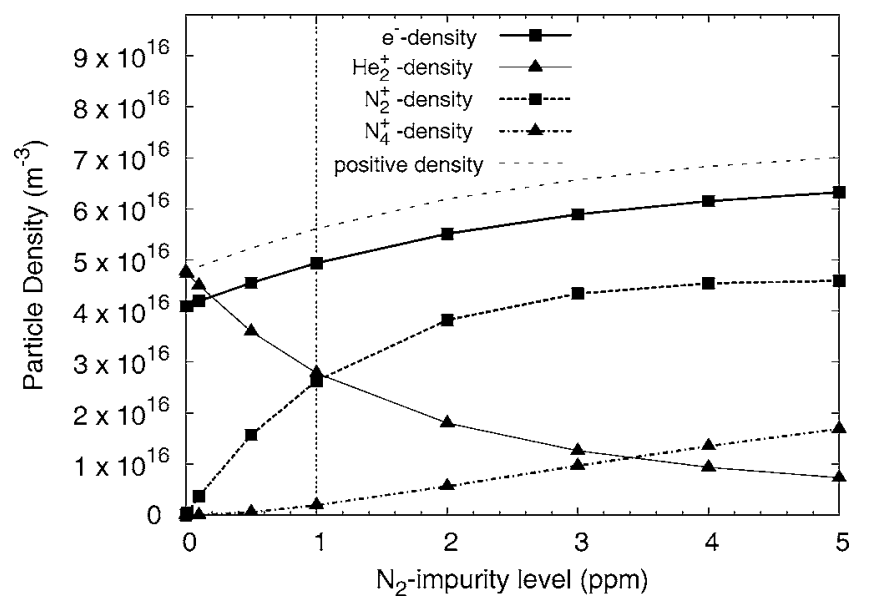

FIG. 1. Calculated time and spatially averaged densities of the important charged particles in an atmospheric DBD in helium with different levels of $\mathrm{N}_{2}$ impurity. The vertical dotted line indicates the boundary between the $\mathrm{He}_{2}^{+}$ governed part and the $\mathrm{N}_{2}^{+}$governed part. The upper dotted curve indicates the sum of the positive ion densities.

properties, a frequency of $10 \mathrm{kHz}$, an applied voltage amplitude of $2 \mathrm{kV}$, and an impurity level of $100 \mathrm{ppm}$ of nitrogen is exactly the same as used by Mangolini et al. ${ }^{1}$ In this case, a periodic discharge is obtained in which every half period, when the gap voltage reaches $1.5 \mathrm{kV}$, a narrow current peak occurs with an amplitude of about $2.5 \mathrm{~mA} / \mathrm{cm}^{2}$. Such current profile is in very good agreement with the experimental current profiles measured by Mangolini et al. ${ }^{1}$ In their experiments, the current peaks occur at the same gap voltage of about $1.5 \mathrm{kV}$, with a somewhat higher current density amplitude of $3.5 \mathrm{~mA} / \mathrm{cm}^{2}$. For this configuration, however, it was not possible in the model to reach breakdown when no nitrogen impurities were present. Periodic discharge behavior was successfully obtained in pure helium when an applied voltage amplitude of $2.6 \mathrm{kV}$ or higher is used. This result confirms that the presence of nitrogen impurities in helium gas has a decreasing effect on the breakdown voltage. ${ }^{14}$

The range of impurity levels under consideration is based on literature. The reported range in literature is quite large with a bottom value of $0.5 \mathrm{ppm}$ (Ref. 3) and an upper value of $0.5 \%$. To our knowledge, all reported values of nitrogen impurities in atmospheric helium are always situated in this range. A very important effect of these impurity levels such as the influence on the breakdown voltage is more or less understood ${ }^{14}$ but concerning the influence on the plasma composition, some questions remain unanswered.

In order to illustrate the significant influence of even small amounts of impurity on the composition, the time and spatial average of the charged particle densities in the discharge are presented in Fig. 1 for impurity levels ranging from 0 to $5 \mathrm{ppm}$. First of all, note that the total positive ion density is about $10 \%-20 \%$ higher than the electron density. As is well known, this can be attributed to the spatial structure of the glow discharge since the plasma sheath is positively charged and the plasma bulk is quasineutral, which cause the spatially averaged charge to be slightly positive. Moreover, both the total ion density and the electron density gradually rise with increasing $\mathrm{N}_{2}$ impurity level for the range shown in Fig. 1. The densities of $\mathrm{He}^{+}$are omitted because these do not achieve values higher than $5 \times 10^{13} \mathrm{~m}^{-3}$. It is also worth to mention that at the instant of maximum current, the electron and total ion densities in the plasma bulk and Downloaded 09 Jan 2009 to 131.155.108.71. Redistribution subject

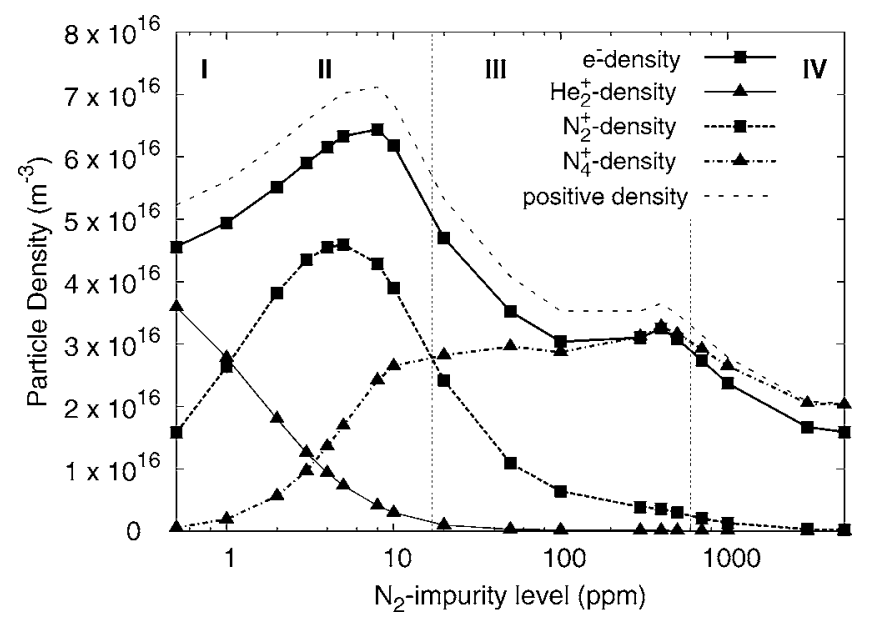

FIG. 2. Calculated time and spatially averaged densities of the important charged particles in an atmospheric pressure helium DBD with nitrogen impurity levels ranging from $0.5 \mathrm{ppm}$ to $0.5 \%$. Region I denotes the $\mathrm{He}_{2}^{+}$ governed part, region II the $\mathrm{N}_{2}^{+}$governed part, region III the $\mathrm{N}_{4}^{+}$governed part with significant $\mathrm{N}_{2}^{+}$contribution, and region IV is completely governed by $\mathrm{N}_{4}^{+}$ions.

presheath are for every nitrogen level to be always in the range from $10^{16} \mathrm{~m}^{-3}$ to $6 \times 10^{17} \mathrm{~m}^{-3}$. This maximum value lies much higher than the values shown in Fig. 1 because the values in Fig. 1 are averaged in time and the APG DBD is a pulsed discharge. This range is in good agreement with the results of similar numerical studies reported in literature $\mathrm{r}^{1,11,13}$ which range from $10^{16} \mathrm{~m}^{-3}$ to $5 \times 10^{17} \mathrm{~m}^{-3}$.

It is clear that only for discharges with less than $1 \mathrm{ppm}$ of nitrogen impurity, the positive charge is determined by the $\mathrm{He}_{2}^{+}$ions. Already at $1 \mathrm{ppm}$ of nitrogen, the time and spatially averaged densities of $\mathrm{He}_{2}^{+}$and $\mathrm{N}_{2}^{+}$ions are the same. At about $3.5 \mathrm{ppm}$ of nitrogen, the $\mathrm{N}_{4}^{+}$ion density also attains a value of the same magnitude as the $\mathrm{He}_{2}^{+}$ion densities. This proves that even small impurity levels have a great effect on the composition of the plasma, since already in the limited range of 0 to $5 \mathrm{ppm}$ of nitrogen impurity, the $\mathrm{He}_{2}^{+}$densities drop from most important ion in the discharge to third-rate ion.

To investigate the effect of impurity levels higher than $5 \mathrm{ppm}$, the time and spatially averaged values of the charged particle densities are plotted in Fig. 2 for the entire simulated range. Since the largest variations occur with the smallest impurity levels, we use a logarithmic scale for the nitrogen levels, ranging from the lowest nonzero value of $0.5 \mathrm{ppm}$ to the highest simulated value of $0.5 \%$. Figure 2 shows that the $\mathrm{He}_{2}^{+}$density drops over the entire range when the relative level of nitrogen in helium gas increases. The $\mathrm{He}_{2}^{+}$ions become negligible in comparison with the nitrogen ions for impurity levels of about $17 \mathrm{ppm}$ or higher. As indicated using Roman numerals and vertical dotted lines in Fig. 2, we divide the impurity dependent profile into four separate regions based on which ions are responsible for the positive charge.

The first region (indicated by I, shown fully in Fig. 1) ranges from zero to $1 \mathrm{ppm}$. In this region, $\mathrm{He}_{2}^{+}$is dominating the positive charge, while $\mathrm{N}_{2}^{+}$has an important role but it is still secondary.

The second region (indicated by II) ranges from 1 to about $17 \mathrm{ppm}$ and shows two important features. First, the ionization degree of the discharge gas reaches a time and spatially averaged maximum of about $3 \times 10^{-9}$ at an impurity
to AIP license or copyright; see http://apl.aip.org/apl/copyright.jsp 


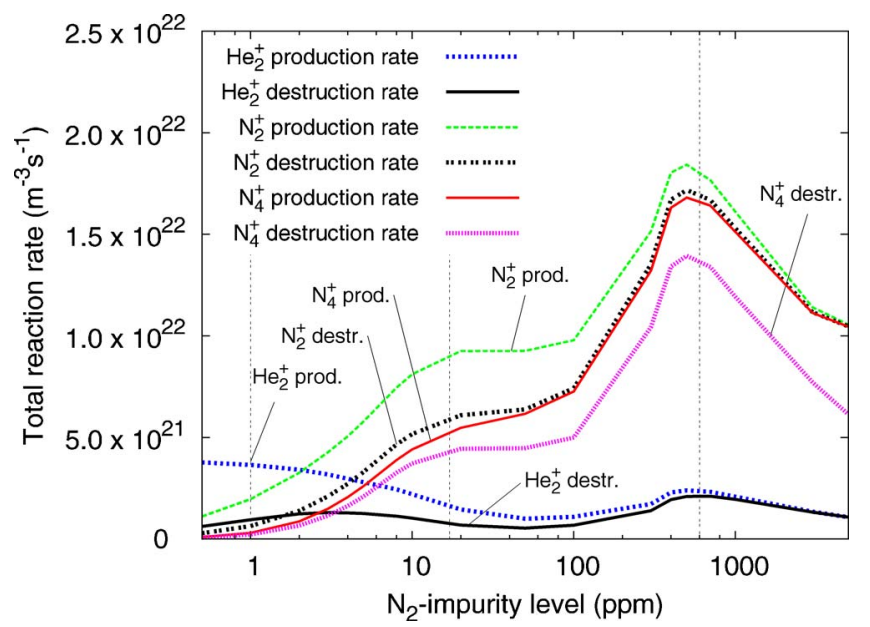

FIG. 3. (Color online) Calculated sums of total production and destruction rates for $\mathrm{He}_{2}^{+}, \mathrm{N}_{2}^{+}$, and $\mathrm{N}_{4}^{+}$.

degree of $8 \mathrm{ppm}$. Second, in this range, the $\mathrm{N}_{2}^{+}$ion determines the positive charge in the discharge, while $\mathrm{He}_{2}^{+} \mathrm{de}-$ creases in this region from a secondary role to almost negligible and $\mathrm{N}_{4}^{+}$rises from an unimportant position to a secondary role in the discharge.

The third region (indicated by III) ranges from about 17 to about $600 \mathrm{ppm}$. The positive charge is now completely governed by the nitrogen ions and $\mathrm{N}_{4}^{+}$has become the most important positive ion in the discharge. The $\mathrm{He}_{2}^{+}$ion densities do not attain values higher than $10^{15} \mathrm{~m}^{-3}$ anymore. We have chosen to designate the boundary of the third region to $600 \mathrm{ppm}$ because for impurity levels higher than this value (i.e., region IV), the $\mathrm{N}_{2}^{+}$densities also have become negligible and the positive charge is completely governed by the $\mathrm{N}_{4}^{+}$ions.

To provide more insights in the underlying mechanisms, we plot in Fig. 3 the time and spatially averaged total production and destruction rates of the $\mathrm{He}_{2}^{+}, \mathrm{N}_{2}^{+}$, and $\mathrm{N}_{4}^{+}$ions. Figure 3 shows that the reason for the decrease in $\mathrm{He}_{2}^{+}$densities in the second region lies in the decrease of the production rate. Our calculations predict that the most important $\mathrm{He}_{2}^{+}$production process at low $\mathrm{N}_{2}$ levels, namely, the selfPenning ionization of $\mathrm{He}_{2}^{*}$ (reaction 17, Table I), becomes unimportant through the loss of $\mathrm{He}_{2}^{*}$ by its Penning ionization of $\mathrm{N}_{2}$ (reaction 18 , Table I) since the time and spatially averaged density of $\mathrm{N}_{2}$ is at 5 ppm already about 150 times bigger than the $\mathrm{He}_{2}^{*}$ density and the ratio keeps increasing with increasing $\mathrm{N}_{2}$ levels. This causes the drop in the $\mathrm{He}_{2}^{+}$ production from 0 to $50 \mathrm{ppm}$, as shown in Fig. 3, and explains the decrease of the $\mathrm{He}_{2}^{+}$density in region II in Fig. 2.

In region II in Fig. $2, \mathrm{~N}_{2}^{+}$determines the positive charge because the $\mathrm{He}_{2}^{+}$density has already dropped significantly, for the reasons mentioned above, and the $\mathrm{N}_{2}$ level is still relatively low. The production of $\mathrm{N}_{2}^{+}$in the second region is for more than $80 \%$ determined by three reactions which are directly depending on the nitrogen partial pressure, namely, the Penning ionizations of $\mathrm{N}_{2}$ by $\mathrm{He}_{m}$ and $\mathrm{He}_{2}^{*}$ and the charge exchange reaction of $\mathrm{He}_{2}^{+}$with $\mathrm{N}_{2}$ (reactions 8, 15, and 18 in Table I). Also, the destruction of $\mathrm{N}_{2}^{+}$is directly influenced by the nitrogen partial pressure since it is increasingly determined by the association of $\mathrm{N}_{2}^{+}$with $\mathrm{N}_{2}$ and $\mathrm{He}$ as a third collision partner (reaction 10, Table I), which is responsible for about $50 \%$ of the $\mathrm{N}_{2}^{+}$destruction at $1 \mathrm{ppm}$ of nitrogen impurity and already for $87 \%$ at 17 ppm of $\mathrm{N}_{2}$.
Consequently, both the production and destruction rise significantly with increasing nitrogen content. However, since the above-mentioned associative reaction is very fast $(k$ $=1.9 \times 10^{-29} \mathrm{~cm}^{6} \mathrm{~s}^{-1}$ ) and depends directly on both background gases, the conversion of $\mathrm{N}_{2}^{+}$to $\mathrm{N}_{4}^{+}$is increasingly promoted, which causes the $\mathrm{N}_{2}^{+}$fraction in the discharge to decrease again. It must be noted that this reaction rate coefficient has been experimentally determined for pressures not higher than 2 mbar, ${ }^{10}$ which can lead to a possible overestimation when used at atmospheric pressure and cause the results to change somewhat quantatively.

Our calculations show that the production of $\mathrm{N}_{4}^{+}$is almost completely determined by the associative collision of $\mathrm{N}_{2}^{+}$with $\mathrm{N}_{2}$ with $\mathrm{He}$ as a third partner (reaction 10, Table I) for every impurity level. This reaction is directly related to the partial pressure of nitrogen. The destruction of $\mathrm{N}_{4}^{+}$is completely governed by the dissociative electron recombination reaction (reaction 6, Table I) and the dissociative collision with $\mathrm{He}$ (reaction 12, Table I), which are not directly related to the partial pressure of nitrogen. Since the abovementioned $\mathrm{N}_{4}^{+}$production reaction is directly related to the nitrogen content and the two destruction reactions are not directly related to the nitrogen content, the $\mathrm{N}_{4}^{+}$fraction in the discharge always increases with rising nitrogen levels.

We have shown in this letter that the influence of common molecular impurities, such as nitrogen in helium gas, is very important even at impurity levels of about $1 \mathrm{ppm}$. Under the assumption that the rate coefficient of the associative conversion of $\mathrm{N}_{2}^{+}$(reaction 10, Table I) may be used as such, it can be concluded from our calculations that the molecular $\mathrm{N}_{4}^{+}$ion, which is often neglected in this kind of studies, becomes even the most important ion in the discharge, if the impurity level is higher than approximately 17 ppm. Finally, we have addressed how the chemical balances shift, which create the different regions in Fig. 2, characterized by different dominating ions and explain how the $\mathrm{N}_{4}^{+}$fraction in the discharge increases when the nitrogen level rises.

We would like to acknowledge the assistance of the Calcua computer facility of the University of Antwerp in the realization of the performed calculations.

${ }^{1}$ L. Mangolini, C. Anderson, J. Heberlein, and U. Kortshagen, J. Phys. D 37, 1021 (2004).

${ }^{2}$ C. Anderson, M. Hur, P. Zhang, L. Mangolini, and U. Kortshagen, J. Appl. Phys. 96, 1835 (2004).

${ }^{3}$ X. Yuan and L. Raja, Appl. Phys. Lett. 81, 814 (2002).

${ }^{4}$ See (http://plasimo.phys.tue.nl).

${ }^{5}$ A. Kossyi, A. Kostinsky, A. Matveyev, and V. P. Silakov, Plasma Sources Sci. Technol. 1, 207 (1992).

${ }^{6}$ BOLSIG, Boltzmann solver for the siglo-series 1.0., CPA Toulouse and Kinema Software, 1996.

${ }^{7}$ I. S. Grigoriev, E. Z. Meilikhov, and A. A. Radzig, Handbook of Physical Quantities (CRC, Boca Raton, Florida, 1997).

${ }^{8}$ H. W. Ellis, R. Y. Pai, E. W. McDaniel, E. A. Mason, and L. A. Viehland, At. Data Nucl. Data Tables 17, 177 (1976).

${ }^{9}$ T. Sommerer and M. Kushner, J. Appl. Phys. 71, 1654 (1992).

${ }^{10}$ D. K. Bohme, D. B. Dunkin, F. C. Fehsenfeld, and E. E. Ferguson, J. Chem. Phys. 51, 863 (1969).

${ }^{11}$ Y. B. Golubovskii, V. A. Maiorov, J. Behnke, and J. F. Behnke, J. Phys. D 36, 39 (2003).

${ }^{12}$ W. J. M. Brok, M. D. Bowden, J. van Dijk, J. J. A. M. van der Mullen, and G. M. W. Kroesen, J. Appl. Phys. 98, 013302 (2005).

${ }^{13}$ F. Massines, A. Rabehi, P. Decomps, R. B. Gadri, P. Ségur, and C. Mayoux, J. Appl. Phys. 83, 2950 (1998).

${ }^{14}$ I. Radu, R. Bartnikas, and M. R. Wertheimer, IEEE Trans. Plasma Sci. 31, 1363 (2003). 